\title{
Application of Computed Tomography (CT) Attenuation Values in Diagnosis of Transudate and Exudate in Patients with Pleural Effusion
}

\author{
Sharma $\mathrm{K}^{1^{\star}}$, Lamichhane $\mathrm{PS}^{1}$, Sharma $\mathrm{BK}^{2}$ \\ 'Department of Radiology, ${ }^{2}$ Department of Microbiology, \\ Gandaki Medical College \& Teaching Hospital, Pokhara, Nepal.
}

\begin{abstract}
Background: Pleural effusion is the pathologic accumulation of fluid in the pleural space. The fluid analysis yields important diagnostic information, and in certain cases, fluid analysis alone is enough for diagnosis. Analysis of pleural fluid by thoracentesis with imaging guidance helps to determine the cause of pleural effusion. The purpose of this study was to assess the accuracy of computed tomography (CT) in characterizing pleural fluid based on attenuation values and CT appearance.
\end{abstract}

Materials and Methods: This prospective study included 100 patients admitted to Gandaki Medical College and Teaching Hospital, Pokhara, Nepal between January 1, 2017 and February 28, 2018. Patients who were diagnosed with pleural effusion and had a chest CT followed by diagnostic thoracentesis within 48 hours were included in the study. Effusions were classified as exudates or transudates using laboratory biochemistry markers on the basis of Light's criteria. The mean attenuation values of the pleural effusions were measured in Hounsfield units in all patients using a region of interest with the greatest quantity of fluid. Each CT scan was also reviewed for the presence of additional pleural features.

Results: According to Light's criteria, 26 of 100 patients with pleural effusions had transudates, and the remaining patients had exudates. The mean attenuation of the exudates $(16.5 \pm 1.7 \mathrm{HU}$; $95 \% \mathrm{CI}$, range, $-33.4-44 \mathrm{HU}$ ) was significantly higher than the mean attenuation of the transudates $(11.6 \pm 0.57 \mathrm{HU}$; $95 \% \mathrm{CI}$, range, 5 - $16 \mathrm{HU}),(\mathrm{P}=0.0001)$. None of the additional CT features accurately differentiated exudates from transudates $(P=0.70)$. Fluid loculation was found in $35.13 \%$ of exudates and in $19.23 \%$ of transudates. Pleural thickening was found

Keywords

Pleural Effusion, Computed Tomography (CT), Thoracentesis, Exudates and Transudates

\section{Corresponding author}

${ }^{*}$ Dr. Keshab Sharma, MD

Lecturer, Department of Radiology

Gandaki Medical College \& Teaching Hospital

Pokhara, Nepal

Email: sharmakes@yahoo.com in $29.7 \%$ of exudates and in $15.3 \%$ of transudates. Pleural nodule was found in $10.8 \%$ of exudates which all were related to the malignancy.

Conclusion: CT attenuation values may be useful in differentiating exudates from transudates. Exudates had significantly higher Hounsfield units in CT scan. Additional signs, such as fluid loculation, pleural thickness, and pleural nodules were more commonly found in patients with exudative effusions and could be considered and may provide further information for the differentiation. 


\section{INTRODUCTION}

Pleural effusion is the pathologic accumulation of fluid in the pleural space which results when forces that control the inflow and outflow of the space are disrupted ${ }^{1}$. Pleural effusion can result from numerous pathologic conditions, such as congestive heart failure, pneumonia, pleuropulmonary malignancy, connective tissue diseases, and trauma ${ }^{2,3}$.

The pleural effusion is evaluated by whether pleural fluid is a transudate or an exudate. Transudate is caused by imbalances in hydrostatic and oncotic forces. The main cause of transudates is usually congestive heart failure (CHF), kidney failure, and cirrhosis. In contrast, exudates occur when local factors influencing the accumulation of pleural fluid are altered. Exudates are due to the increased capillary permeability and/or impaired lymphatic drainage which results from the proliferative (e.g. malignancy) or inflammatory (e.g. parapneumonic effusions) processes ${ }^{4}$.

Diagnostic thoracentesis is performed to determine the specific cause of a pleural effusion and supplies biochemistry measurements (e.g. protein and LDH) that help to separate effusions into transudates and exudates. Further analysis such as cytology and cultures may help in establishing the specific cause of the effusion ${ }^{5}$. Though diagnostic thoracentesis is considered a relatively safe procedure, it is associated with risks such as pneumothorax and has several contraindications such as coagulopathy ${ }^{6,7,8}$. Thus, a noninvasive method to characterize pleural fluid would be valuable for avoiding the potential risks associated with thoracentesis and may help to guide therapy. In addition, such a method could help with diagnosis in patients with a contraindication for the invasive procedure.

The differential diagnosis of pleural effusions can be conducted by means of thoracentesis, pleural biopsies, and occasionally diagnostic thoracoscopy ${ }^{9}$ and imaged by radiography ${ }^{10}$, ultrasonography ${ }^{11}$ or computed tomography $(\mathrm{CT})^{12}$. Noninvasive procedure like CT scan be useful in determining the causes of pleural effusions ${ }^{13,14}$. CT is commonly used to evaluate patients with pleural abnormalities related to neoplasm, pneumonia, and empyema $^{15}$. Indeed, CT can be used to evaluate the nature of pleural effusions to avoid the complications of thoracentesis ${ }^{6,7}$.

Features such as pleural nodules, pleural thickening, loculation, and effusion density can be evaluated by CT to discriminate between exudates and transudates ${ }^{16}$.
Analysis of pleural fluid by thoracentesis with imaging guidance helps to determine the cause of pleural effusion. In this regard, the objective of this study was to assess the utility of Multidetector Computed Tomography (MDCT) examinations in characterizing pleural effusions on the basis of attenuation values and CT appearance.

\section{MATERIALS AND METHODS}

\section{Study design and patient selection}

The study protocol was reviewed and approved by the Gandaki Medical College and Teaching Hospital's Institutional Ethics Committee. This prospective study included patients who had a chest CT followed by diagnostic thoracentesis within 48 hours who visited between January 1, 2017 and Feb 28, 2018. Informed consent was obtained from the each patient for this study.

The patients were categorized into transudates and exudates groups according to the types of pleural effusion by using Light's criteria $^{17}$, which diagnoses exudates pleural fluid when one or more of the following criteria is meet: (a) a pleural fluid total protein/serum total protein ratio $>0.5$, (b) pleural fluid lactic dehydrogenase (LDH)/ serum $\mathrm{LDH}$ ratio $>0.6$, or (c) pleural fluid LDH $>$ two-thirds of the upper limits of the normal serum LDH value. CT attenuation value (CTA) in Hounsfield Unit (HU) was taken using a region of interest on the CT chest with the greatest quantity of fluid. Each CT scan was also reviewed for the presence of additional pleural features such as pleural thickening, loculation and pleural nodule.

\section{Inclusion Criteria}

This study included patients with pleural effusions on CT scan and who underwent diagnostic thoracentesis within 48 hours.

\section{Exclusion Criteria}

The patients were excluded from this study who underwent insertion of intercostals drainage before CT examination, and who had uncertain final diagnosis, had contrast media allergy, had serum creatinine greater 1.5 $\mathrm{mg} / \mathrm{dl}$, or had pregnancy.

\section{CT protocol and imaging analysis}

The pleural fluid CT attenuation value (CTA) in Hounsfield Unit were taken by using the average measure of the 
three slices with the greatest quantity of fluid, which was determined by the largest anteroposterior diameter of the pleural effusion. A region of interest was placed for measurement of Hounsfield unit values of the maximal amount of fluid on each (Fig 1, 2 and 3). The Radiologist took care not to include adjacent ribs, lung parenchyma, or areas of pleural thickening.

Fig 1: Enhanced axial chest CT scan of 67 years old female presenting right lung mass with right pleural effusion with pleural nodule and CT attenuation value is 17

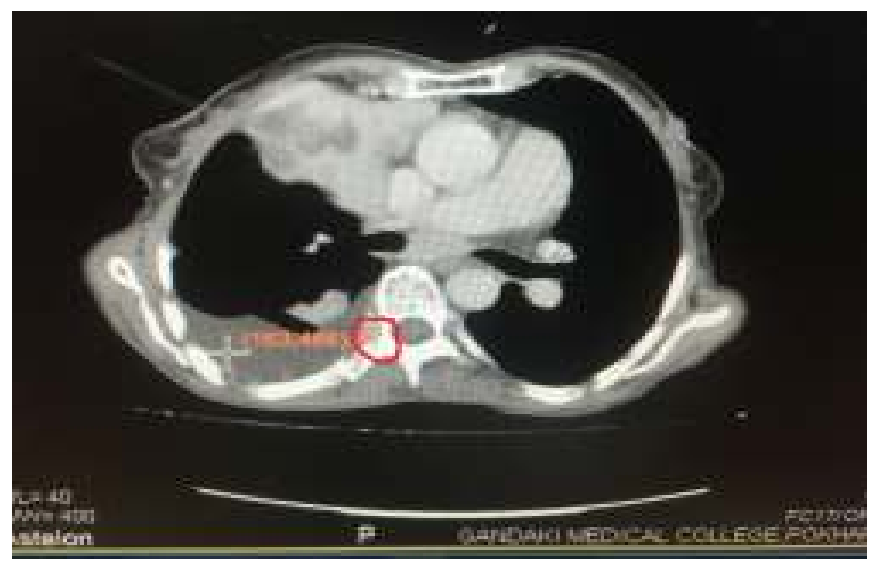

Fig 2: Unenhanced axial chest CT scan of 60 years old male presenting left side empyema with loculation and CT attenuation value is 25.3

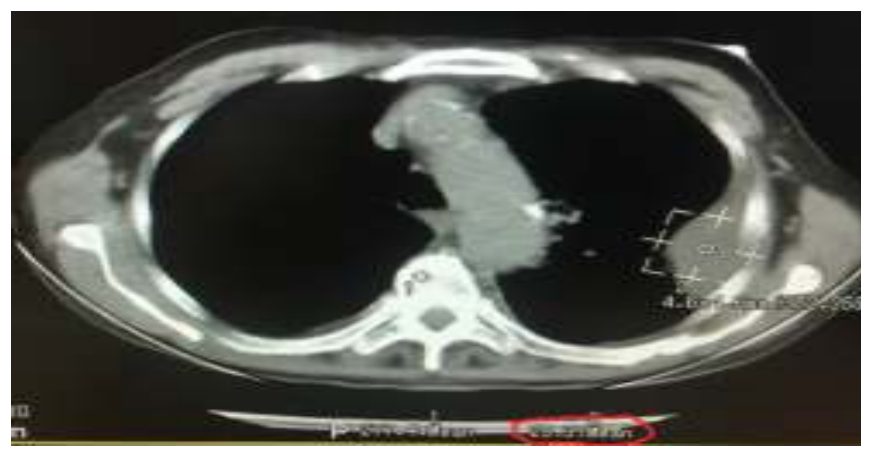

Fig 3: Enhanced axial chest CT scan of 72 years old female diagnosed as CCF (Congestive cardiac failure) presenting with right pleural effusion. CT attenuation value is 10

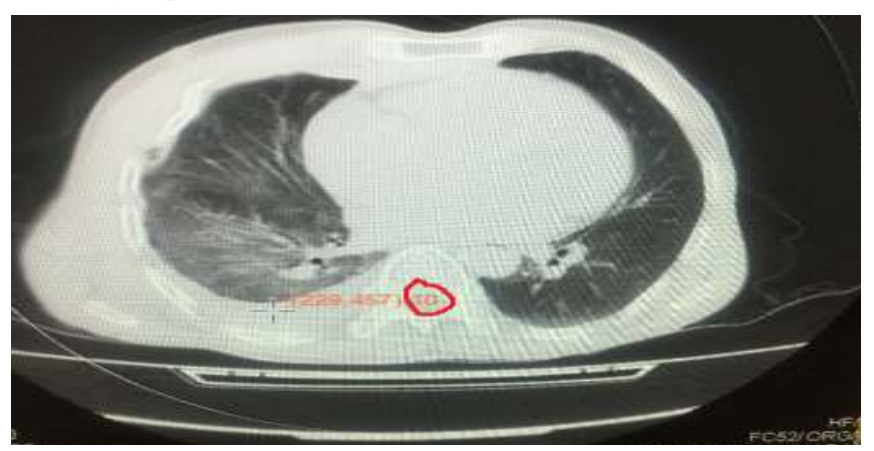

CT was performed on all patients using Toshiba Asteion 4 slice scanner, Japan. The protocol used for this scanning was contiguous axial $4 \mathrm{~mm}$; pitch of $1 ; 120 \mathrm{kV}$; and automated mAs. IV contrast material was not administered when renal function tests were abnormal, in patients with high risk for contrast nephropathy (Dehydration, diabetes mellitus etc.), in patients with an allergy to contrast material, or when the indication for CT did not necessitate the use of contrast material. IV contrast material was administered in standard injection protocol $(100 \mathrm{~mL}$ of iohexol $350 \mathrm{mg} \mathrm{I} / \mathrm{ml}$ ) at $1-2 \mathrm{ml} / \mathrm{kg}$ with an injection rate of $3 \mathrm{~mL} / \mathrm{s}$.

\section{Statistical Analysis}

All samples data were tabulated in a master chart and entered in data sheet Graph pad prism version 7. Statistical analysis was carried out with Graph pad prism; a computer software program. The data were expressed as mean. Two tailed T-test were used for correlation between types of pleural effusion and mean attenuation value in pre and post contrast CT images. Receiver operating characteristic (ROC) curve was applied to find the CT attenuation values for exudates and cut-off point was identified using the ROC curve nearest to the point at which sensitivity and specificity were maximized. One way ANOVA test was applied for determining the correlation between subgroups of exudates pleural effusion and mean attenuation coefficient. Statistical significance was defined as $\mathrm{P}<0.05$.

\section{RESULTS}

There were 100 people subjected to this study who were from different parts of the Western Region of Nepal. Among them 62 out of 100 were males (62\%) and 38 out of 100 were females (38\%). Among them youngest patient was 10 years old and oldest patient was 89 years old. The demographic and CT findings in patients with exudative and transudative effusions are shown in Table 1, Table 2 and Fig 4.

Table 1: Demographic and CT findings of the patients

\begin{tabular}{llll}
\hline & & Min - Max & \\
Age (Years) & & $\mathbf{1 0}$ to $\mathbf{8 9}$ & \\
CT attenuation (HU) & & $-\mathbf{3 2 . 4}$ to $\mathbf{4 4}$ & \\
& & Number (N) & Percentage (\%) \\
Gender & Males & 62 & $62 \%$ \\
Pleural thickening & Females & 38 & $38 \%$ \\
Pleural nodules & & 26 & $26 \%$ \\
\hline
\end{tabular}




\begin{tabular}{|c|c|c|c|}
\hline Loculation & & 31 & $31 \%$ \\
\hline Empyema & & 14 & $14 \%$ \\
\hline Tuberculosis & & 26 & $26 \%$ \\
\hline Malignancy & & 32 & $32 \%$ \\
\hline CHF & & 8 & $8 \%$ \\
\hline Simple Pneumonia & & 18 & $18 \%$ \\
\hline Lipoid Pneumonia & & 2 & $2 \%$ \\
\hline \multirow{2}{*}{ Effusion } & Transudates & 26 & $26 \%$ \\
\hline & Exudates & 74 & $74 \%$ \\
\hline
\end{tabular}

Table 2: Demographic and CT Findings of the patients with exudative and transudative effusion

\begin{tabular}{lccc} 
& $\begin{array}{c}\text { Patient with } \\
\text { transudates }\end{array}$ & $\begin{array}{l}\text { Patient } \\
\text { with } \\
\text { exudates }\end{array}$ & P value \\
$\begin{array}{l}\text { Gender (Male/ } \\
\text { Female) }\end{array}$ & $17 / 9$ & $45 / 29$ & \\
$\begin{array}{l}\text { Age (Years) } \\
\text { CT attenuation } \\
\text { value (HU) }\end{array}$ & $10-65$ & $17-89$ & \\
$\begin{array}{l}\text { Pleural nodule } \\
\begin{array}{l}\text { Pleural thick- } \\
\text { ening }\end{array}\end{array}$ & 0 & 16.5 & $<, 0.0001^{* * * *}$ \\
Loculation & 4 & 8 & 0.70 \\
\hline
\end{tabular}

Fig 4: Box plots showing attenuation value for transudates and exudates groups. The vertical line across the each box is showing mean value

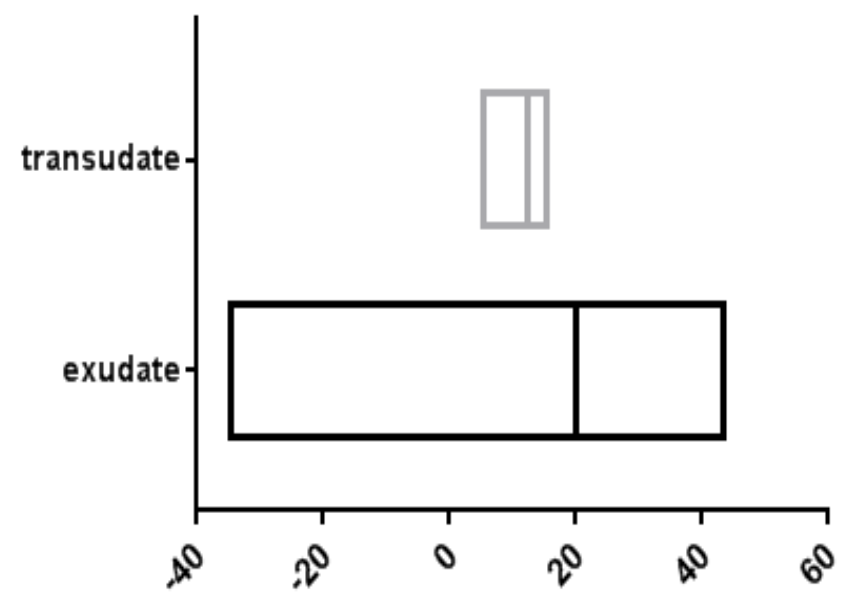

The mean HU values of the exudates were significantly higher than those of the transudates ( $\mathrm{P}=0.0001)$. Intravenous contrast agent was used in 18 of 26 patients with transudative effusions (69.23\%) and 71 of 74 patients with exudative effusions (95.9\%). In patients with exudates, mean attenuation was $16.5 \pm 1.7 \mathrm{HU}$ for those who received a contrast injection $(n=71)$ and $15.5 \pm 0.5$ HU for those who did not $(n=3)$.

In patients with transudates, mean attenuation was 11.6 $\pm 0.57 \mathrm{HU}$ for those who received a contrast injection ( $\mathrm{n}=$ 18 ) and $10.5 \pm 0.2 \mathrm{HU}$ for those who did not $(\mathrm{n}=8)$. The analysis revealed that the intravenous contrast agent did not much affect the HU values $(P=0.7925)$. When the cut off value for exudative effusion was accepted as $\geq 15.3 \mathrm{HU}$, the sensitivity and specificity were $81.08 \%$ and $100 \%$, respectively (AUC, 0.8784; 95\% CI, 0.7 - 0.89).

Loculation was found in five of 26 (19.2\%) patients who was diagnosed as transudate and 26 out of 74 (35.13\%) who were diagnosed as exudative fluid. Pleural nodules were found in eight out of $74(10.8 \%)$ patients who were diagnosed as exudative fluid especially on those patients who were suffer from lung malignancy.

Pleural thickening was found in four out of 26 (15.3\%) who diagnosed as transudative whereas 22 out of 74 (29.7\%) patients who diagnosed as exudative pleural effusion. As comparing between exudative and transudative pleural effusion, the exudative effusions had higher frequency of loculation, pleural thickening and pleural nodules.

The demographic and CT findings of patients with CHF, pneumonia, pulmonary tuberculosis (PTB), malignancy, and empyema are shown in Table 3. The diagnostic performance of the HU values in defining the subgroups of patients with pleural effusions was evaluated using ROC analysis. When the cut of value accepted as $\geq 15.3 \mathrm{HU}$, the sensitivity and specificity of РТВ (80.7\% and 100\%), malignancy (81.2\% and 100\%) and empyema (92.8\% and $100 \%$ ) were obtained. Whereas cut off value transudative effusion was accepted as < $15.3 \mathrm{HU}$, the sensitivity and specificity of CCF (97\% and 100\%) and pneumonia (94.4\% and $100 \%$ ) were obtained.

One way ANOVA test was applied for determining the correlation among sub group of exudates empyema, pulmonary tuberculosis and malignancy and mean attenuation coefficient which showed there were no significant correlation between subgroups of exudative pleural effusion with its mean coefficient value $(p=0.57)$.

Table 3: Demographic and CT findings of the patient with CHF, pneumonia, PTB, malignancy and empyema

\begin{tabular}{lccccc}
\hline & $\begin{array}{l}\text { Patients } \\
\text { with CHF } \\
(\mathrm{n}=8)\end{array}$ & $\begin{array}{l}\text { Patients } \\
\text { with } \\
\text { pneumonia } \\
(\mathrm{n}=20)\end{array}$ & $\begin{array}{l}\text { Patients } \\
\text { with PTB }(\mathrm{n})\end{array}$ & $\begin{array}{l}\text { Patients } \\
\text { with } \\
\text { empyema } \\
(\mathrm{n}=14)\end{array}$ & $\begin{array}{l}\text { Patients } \\
\text { with } \\
\text { malignancy } \\
(\mathrm{n}=32)\end{array}$ \\
$\begin{array}{l}\text { Gender } \\
\text { Male/female }\end{array}$ & $5 / 3$ & $13 / 7$ & $20 / 6$ & $9 / 5$ & $21 / 11$ \\
Age (years) & $40-72$ & $10-55$ & $17-75$ & $33-71$ & $43-89$
\end{tabular}




\begin{tabular}{lccccc}
$\begin{array}{l}\text { CT attenua- } \\
\text { tion HU }\end{array}$ & 8.4 & 13.0 & 16.7 & 21.1 & 17.0 \\
$\begin{array}{l}\text { Pleural } \\
\text { nodule }\end{array}$ & 0 & 0 & 0 & 0 & 8 \\
$\begin{array}{l}\text { Pleural thick- } \\
\text { ening }\end{array}$ & 1 & 3 & 8 & 5 & 9 \\
\begin{tabular}{l} 
Loculation \\
\hline
\end{tabular} & 1 & 4 & 7 & 14 & 5 \\
\hline
\end{tabular}

\section{DISCUSSION}

The space between parietal and visceral pleura is known as pleural space. Normally $7-14 \mathrm{ml}$ of pleural fluid is found in the pleural space ${ }^{18}$. Accumulation of pleural fluid more than normal limit occurs when rate of the fluid formation exceeds the rate of the fluid removal. This may mostly result from either of increase of hydrostatic pressure (transudate) or increase of permeability of the pleural vessel (exudates) ${ }^{19}$. Differentiation between exudative and transudative pleural fluid relies on chemical analysis of pleural fluid and blood, by using Light criteria ${ }^{17}$. CT is commonly used tool for assessing the patient presenting with pleural abnormalities ${ }^{15}$. CT scan is not only useful tool for detecting type of pleural effusion but also useful for detecting the causes of pleural effusion and its associated lung, mediastinal and heart disease $\mathrm{e}^{13,14}$.

Thereareseveralstudies which found the clinical application of the CT scan for differentiation between transudative and exudative pleural effusion by using $\mathrm{CT}$ attenuation value. The previous studies conducted by Nandalur et $a l^{20}$ and Cullu et $a l^{21}$ demonstrated the significant higher mean CT attenuation value of exudates (13.6 - $17.1 \mathrm{HU})$, compared with the transudates ( 6 - $12.5 \mathrm{HU}$ ). However Abramowitz et $a l^{22}$ demonstrated the lower mean attenuation values of exudates $(7.2 \pm 9.4 \mathrm{HU})$, compared with transudates (10.1 $\pm 6.9 \mathrm{HU}$ ) without statistical significant.

The results obtained in this study were similar to the prior studies ${ }^{20,21}$ which showed significant higher mean attenuation values of exudates $(16.5 \pm 1.7 \mathrm{HU}$ in postcontrast images and $15.5 \pm 0.5 \mathrm{HU}$ in pre-contrast images), compared with the transudates $(11.6 \pm 0.57 \mathrm{HU}$ in postcontrast images and $10.5 \pm 0.2 \mathrm{HU}$ in pre-contrast images). The mean attenuation values in post-contrast CT images were approximately one $\mathrm{HU}$ higher than those in precontrast images, which represented the small effect of intravenous contrast material to the mean attenuation values. Similar to the previous study done by Abramowitz et $a^{22}$, this study also obtained negative attenuation value in nine out of 74 exudative fluid, among them two cases were lipoid pneumonia and seven cases were lung malignancy.

There are different reasons for causing elevation of pleural cholesterol in exudates rather than elevation of serum cholesterol level. Best possible reason for increased pleural cholesterols level may be due to greater cellular degeneration or increased pleural permeability in underlying disease e.g. malignancy, pneumonia or tuberculosis ${ }^{23}$. Other possible cause for elevating cholesterol levels can also result from chylothorax, mainly due to trauma or lymphoma, and from pseudochylothorax, mainly due to tuberculosis, rheumatoid arthritis, or empyema ${ }^{24}$. Since fat tissue demonstrate negative attenuation values. Thus, the high concentration of protein in exudates that is expected to raise the attenuation values may be contradicted by the high cholesterol level that decreases the CT attenuation value. We could not determine whether our negative attenuation fluids had high levels of cholesterol because pleural cholesterol was measured in only seven out of the 100 patients.

Arenas-Jimenez et a ${ }^{16}$ reported that CT findings, such as loculation and pleural thickening, appeared more frequently in empyemas but also occurred in pneumonic effusions; therefore, these findings cannot be used as a distinguishing feature. However, Cullu et $a l^{21}$ found that patients with empyemas had a significantly higher frequency of loculation and pleural thickening than other patients. In our study, there was no statistically significant difference in the frequency of pleural loculation and pleural thickening between empyema patients and other patients. However, it was found that the frequency of loculation in patients with empyema was higher than that seen in patients without empyema, although this difference was not statistically significant $(\mathrm{p}=0.056)$.

The authors Aquino et $a l^{15}$, Arenas-Jimenez ${ }^{16}$ and Waite et $a l^{25}$ found that the presence of pleural thickening, pleural nodules and loculation were highly specific for exudates. Similarly, Cullu et a ${ }^{21}$ reported that exudates had a significantly higher frequency of loculation and pleural thickening compared to that of transudates. However, Abramowitz et al ${ }^{22}$ found pleural thickening in 8 out of 22 transudates (36\%) compared to 46 out of 78 exudates (59\%), and loculated pleural effusion in eight of the 22 transudates (36\%) compared with 45 of the 78 exudates (58\%). Both pleural thickening and loculation were found in more than one-third of patients with transudates, 
which was not in line with previous studies. In our study, similarly to Abramowitz et a ${ }^{22}$, we found that the presence of pleural thickening, pleural nodules and loculation were not reliable findings for characterizing pleural effusions though frequency of pleural thickening, loculation and pleural nodules were higher in exudative pleural effusion.

\section{CONCLUSION}

In conclusion, we believe that $\mathrm{CT}$ attenuation values may be useful in differentiating exudates from transudates. Although there is an overlap in the majority of effusions, exudates can be considered with CT attenuation values $>15.3 \mathrm{HU}$, Because of overlapping HU values, close correlation with clinical findings is essential. Additional signs, such as fluid loculation, pleural thickness. Pleural nodule may provide additional information for the differentiation.

\section{Conflict of Interest}

The authors do not have any conflict of interest to declare.

\section{REFERENCES}

1. Raasch BN, Carsky EW, Lane EJ, O'Callaghan JP, Heitzman ER. Pleural effusion: Explanation of some typical appearances. Ajr Am J Roentgenol. 1982; 139: 899-904.

2. Fraser RS, Muller NL, Colman N, Paré PD. Diagnosis of Diseases of the Chest. 4th ed. Philadelphia, PA: W.B. Saunders Company; 1999.

3. Henschke CI, Davis SD, Romano PM, Yankelevitz DF. The pathogenesis, radiologic evaluation, and therapy of pleural effusions. Radiol Clin North Am. 1989; 27 (6): 1241 - 1255.

4. Light RW. Clinical practice. Pleural effusion. $N$ Engl J Med. 2002; 346: 1971-1977.

5. Bartter T, Santarelli R, Akers SM, Pratter MR. The evaluation of pleural effusion. Chest. 1994; 106: 1209-1214.

6. Grogan DR, Irwin RS, Channick R, Raptopoulos V, Curley FJ, Bartter T, Corwin RW. Complications associated with thoracentesis. A prospective, randomized study comparing three different methods. Arch Intern Med. 1990; 150: 873-877.

7. Collins TR, Sahn SA. Thoracocentesis: Clinical value, complications, technical problems, and patient experience. Chest. 1987; 91: 817-822.

8. Sokolowski JW, Burgher LW, Jones FL, Patterson JR, Selecky PA. Guidelines for thoracentesis and needle biopsy of the pleura. Am Rev Respir Dis. 1989; 140:257-258.

9. Colt HG. Thoracoscopic management of malignant pleural effusions. Clin Chest Med. 1995; 16: 505518.

10. Light RW. Clinical practice. Pleural effusion. $N$ Engl J Med. 2002; 346 (25): 1971 - 1977.

11. Feller-Kopman D. Ultrasound-guided thoracentesis. Chest. 2006; 129 (6): 1709 - 1714.

12. Hansell DM, Lynch DA, McAdams HP, Bankier AA. Imaging of Diseases of the Chest. 5th ed. Philadelphia, PA: Mosby Elsevier; 2010.

13. Heffner JE, Brown LK, Barbieri CA. Diagnostic value of tests that discriminate between exudative and transudative pleural effusions. Chest. 1997; 111: 970-980.

14. Romero S, Candela A, Martín C, Hernández L, Trigo C, Gil J. Evaluation of different criteria for the separation of pleural transudates from exudates. Chest. 1993; 104: 399-404.

15. Aquino SL, Webb WR, Gushiken BJ. Pleural exudates and transudates: Diagnosis with contrast enhanced CT. Radiology. 1994; 192: 803-808.

16. Arenas-Jiménez J, Alonso-Charterina S, SánchezPayá J, Fernández-Latorre F, GilSánchez S, LloretLlorens M. Evaluation of CT findings for diagnosis of pleural effusions. Eur Radiol. 2000; 10: 681690.

17. Light RW, Macgregor MI, Luchsinger PC, Ball WC Jr. Pleural effusions: the diagnostic separation of transudates and exudates. Ann Intern Med. 1972; 77: 507-513.

18. Light RW, Girard WM, Jenkinson SG, George RB. Parapneumonic effusions. Am J Med. 1980; 69: 
507-512.19.

19. Sahn SA. State of the art: The pleura. Am Rev Respir Dis. 1988; 138: 184-234.

20. Nandalur KR, Hardie AH, Bollampally SR, Parmar JP, Hagspiel KD. Accuracy of computed tomography attenuation values in the characterization of pleural fluid: An ROC study. Acad Radiol. 2005; 12: 987-91.

21. Cullu N, Kalemci S, Karakas O, Eser I, Yalçın F, Boyacı FN, Karakaş E. Efficacy of CT in diagnosis of transudates and exudates in patients with pleural effusion. Diagn Interv Radiol. 2014; 20: 116-20.

22. Abramowitz Y, Simanovsky N, Goldstein MS, Hiller N. Pleural effusion: Characterization with CT attenuation values and CT appearance. Ajr Am J Roentgenol. 2009; 192: 618-23.

23. Hamm H, Brohan U, Bohmer R, Missmahl HP. Cholesterol in pleural effusions. Chest. 1987; 92: 296-302.

24. Agrawal V, Sahn SA. Lipid pleural effusions. Am J Med Sci. 2008; 335: 16-20.

25. Waite RJ, Carbonneau RJ, Balikian JP, Umali CB, Pezzella AT, Nash G. Parietal pleural changes in empyema: Appearances at CT. Radiology. 1990; 175: 145-150. 